\title{
Violent Video Games, Externalizing Behavior, and Prosocial Behavior: A Five-Year Longitudinal Study During Adolescence
}

\author{
Sarah M. Coyne \\ Brigham Young University - Provo, smcoyne@byu.edu \\ Wayne A. Warburton \\ Macquarie University \\ Lee W. Essig \\ Brigham Young University - Provo \\ Laura A. Stockdale \\ Brigham Young University - Provo \\ Follow this and additional works at: https://scholarsarchive.byu.edu/facpub \\ Part of the Child Psychology Commons, and the Other Social and Behavioral Sciences Commons

\section{Original Publication Citation} \\ Coyne, S. M., Warburton, W. A., *Essig, L. W., \& Stockdale, L. A. (2018). Violent video games, \\ externalizing behavior, and prosocial behavior: A five-year longitudinal study during \\ adolescence. Developmental Psychology, 54, 1868-1880.
}

\section{BYU ScholarsArchive Citation}

Coyne, Sarah M.; Warburton, Wayne A.; Essig, Lee W.; and Stockdale, Laura A., "Violent Video Games, Externalizing Behavior, and Prosocial Behavior: A Five-Year Longitudinal Study During Adolescence" (2018). Faculty Publications. 4015.

https://scholarsarchive.byu.edu/facpub/4015

This Peer-Reviewed Article is brought to you for free and open access by BYU ScholarsArchive. It has been accepted for inclusion in Faculty Publications by an authorized administrator of BYU ScholarsArchive. For more information, please contact ellen_amatangelo@byu.edu. 


\title{
Violent Video Games, Externalizing Behavior, and Prosocial Behavior: A Five-Year Longitudinal Study During Adolescence
}

\author{
Sarah M. Coyne \\ Brigham Young University
}

\author{
Wayne A. Warburton \\ Macquarie University
}

\author{
Lee W. Essig and Laura A. Stockdale \\ Brigham Young University
}

\begin{abstract}
Decades of research on the effects of media violence have examined associations between viewing aggressive material in the media and aggression and prosocial behavior. However, the existing longitudinal studies have tended to exclusively examine aggression and prosocial behavior as outcomes, with a limited range of potential mediators. The current study examines associations between playing violent video games and externalizing and prosocial behavior over a 5-year period across adolescence. Additionally, the study examines potential mediators of these associations, including empathic concern, benevolence, and self-regulation. Participants included 488 adolescents $\left(M_{\text {age }}\right.$ of child at Wave $1=$ $13.83, S D=0.98$ ) and their parents, who completed self- and parental measures at three different time points, each 2 years apart. Results revealed that early exposure to video game violence was indirectly associated with lower levels of prosocial behavior as mediated by lower levels of benevolence. Additionally, early video game violence play was associated with higher levels of externalizing behavior at the cross-sectional level, but not 5 years later. Implications of results for adolescents and parents are discussed.
\end{abstract}

Keywords: video game, computer game, externalizing behavior, violence, prosocial

Supplemental materials: http://dx.doi.org/10.1037/dev0000574.supp

Media has been used for many years to convey messages to its audiences. However, in just the past few decades, media use has increased dramatically. A recent United States poll showed that, on average, children aged 8-12 years were exposed to almost six hours per day of recreational media, including over four and a half hours of screen time. Teens aged 13-18 years were exposed to considerably more: almost nine hours of recreational media and more than six and a half hours of screen time (Rideout, 2015). In recent years, media and its potential effects on users have been investigated in many forms, and researchers have found that exposure to different media content has been linked with a range of

Sarah M. Coyne, School of Family Life, Brigham Young University; Wayne A. Warburton, Department of Psychology, Macquarie University; Lee W. Essig and Laura A. Stockdale, School of Family Life, Brigham Young University.

We thank the Family Studies Center, the School of Family Life, and the College of Family, Home, and Social Sciences at Brigham Young University, and recognize the generous support of the many private donors who provided assistance for this project. We also thank those families who were willing to spend valuable hours with our team in interviews and the many students who assisted in conducting the interviews.

Correspondence concerning this article should be addressed to Sarah M. Coyne, School of Family Life, Brigham Young University, JFSB 2086C, Provo, UT 84602. E-mail: smcoyne@byu.edu positive and negative outcomes. Media can be educational (Schmidt \& Anderson, 2007), enhance aspects of cognitive development and fine motor skills (Green \& Bavelier, 2006), be a focus point for social connections and personal identity (Roe, 1996; Warburton, 2012; Warburton \& Highfield, 2016), and be a model for prosocial behavior (Greitemeyer \& Mügge, 2014; Prot et al., 2014). However exposure to other types of media content has been associated with negative outcomes, including substance use (Padilla-Walker, Nelson, Carroll, \& Jensen, 2010; Robinson, Chen, \& Killen, 1998), violence (Anderson et al., 2003), aggression (Anderson, Bushman, Donnerstein, Hummer, \& Warburton, 2015; Media Violence Commission, International Society for Research on Aggression, 2012; Warburton \& Braunstein, 2012), risky behavior (Klein et al., 1993), and increased and accelerated sexual behaviors (Escobar-Chaves et al., 2005; Pardun, L'Engle, \& Brown, 2005).

In addition to increased exposure to media, advancements in technology have brought about more sophisticated forms of media and different ways to interact with them. Video games are a newer form of interactive media that, year by year, have used more advanced technology for their delivery and more sophisticated and realistic graphics for their content (Konijn, Bijvank, \& Bushman, 2007). Because video games are interactive, some researchers have suggested that video games may be more likely to influence outcomes such as aggression and decreased empathy than more passive media (Bryant \& Oliver, 2009). It is important to note that 
some researchers have argued that exposure to violent video games are not a significant predictor of aggressive or violent behavior in the short, or long term (e.g., DeCamp \& Ferguson, 2017; Ferguson, 2007; Markey \& Ferguson, 2017), yet the majority of researchers studying media effects affirm the existence of a positive relationship between exposure to violent media and increased aggressive behavior (Greitemeyer \& Mügge, 2014). This interactive exposure to media using video games, in turn, may have developmental implications where the content is unhelpful in terms of socialization and moral development. For example, many popular video games have been shown to have frequent depictions of violence (Dill, Gentile, Richter, \& Dill, 2005) as well as sexual (Downs \& Smith, 2010) and antisocial content (Walsh, Gentile, Gieske, Walsh, \& Chasco, 2003). The current study will investigate longitudinal associations between playing high amounts of violent video games and various positive and negative outcomes, including externalizing behavior and prosocial behavior, over a 5 -year period in adolescence.

\section{Violent Video Games}

Violent content appears in many genres of video games, including children's games and educational games. According to a Children Now (2001) content analysis, as much as $89 \%$ of video games have some form of violence, with almost half including potentially lethal violence against other characters (Dill et al., 2005; Gentile, Lynch, Linder, \& Walsh, 2004). Many studies have investigated the effects of violent video games on several different outcomes. The majority of these studies have suggested that violent video game play is positively associated with aggression (e.g., Anderson \& Warburton, 2012; Greitemeyer \& Mügge, 2014; Warburton, 2014), violence (Bartholow, Bushman, \& Sestir, 2006), hostility (Gentile et al., 2004), aggressive affect (Anderson \& Bushman, 2001), and desensitization to violent depictions and messages (Bartholow et al., 2006; Carnagey, Anderson, \& Bushman, 2007; Gentile, Swing, Anderson, Rinker, \& Thomas, 2016). Similar findings have been reported across cultures (Anderson et al., 2010) in dozens of countries (Anderson et al., 2008, 2017; Möller \& Krahé, 2009).

\section{Violent Video Games and Externalizing Behaviors}

While both cross-sectional and longitudinal studies have correlated violent video game use with aggression and other negative outcomes, very little research has investigated the potential relationships between violent video games and externalizing behaviors. Externalizing behaviors are conceptualized as including a variety of behaviors and activities including social deviance, unmanageability, hyperactivity, disruptiveness, noncompliance, antisocial behaviors, and delinquency (Maughan, Christiansen, Jenson, Olympia, \& Clark, 2005). Given the scope of externalizing behaviors and the developmental issues related to externalizing behaviors (e.g., Campbell, Shaw, \& Gilliom, 2000), it is important to understand contributing social factors, including violent video game play. While some research combines aggression and externalizing behaviors as indicators of problem behavior, there is evidence to suggest that these are two distinctive constructs that are differentially associated with outcomes. For example, the definition of aggression includes an intent to harm others. Conversely, externalizing behavior can harm others but is more focused on rule-breaking behavior, and can include behaviors such as theft, drug or other substance use, truancy, and so forth. A numbers of studies utilizing factor analyses have found that aggression and externalizing behavior load on two different dimensions (e.g., Rey \& Morris-Yates, 1993; Tackett, Krueger, Sawyer, \& Graetz, 2003), leading to a much more accurate representation of antisocial behavior than examining these in one dimension. However, though aggression and externalizing behavior often load as two distinct dimensions, they are often highly correlated. Violent video games depict a significant amount of aggression while often displaying high levels of externalizing behaviors, such as vandalism, theft, and general rule breaking. Accordingly, an early and heavy diet of violent video games-which are often replete with nonviolent externalizing behaviors - may increase the likelihood that individuals would learn that such externalizing behaviors are normative and even rewarded in some circumstances. Thus, we have decided to examine the long-term effect of violent video games on externalizing behavior in the current study.

To our knowledge, only a few studies have explicitly investigated the relationship between violent video games and externalizing behaviors. The first, conducted by Funk et al. (2002), did not find any significant relationship between violent video games and externalizing behaviors. Another study found a positive association between violent games and externalizing behaviors but only among females (Lohaus, Ball, Klein-Hessling, \& Wild, 2005). Lastly, a study conducted by Holtz and Appel (2011) found that externalizing behavior problems like aggression and delinquency could be predicted based on online gaming and first-personshooter game play.

Several researchers have examined the relationship between playing violent video games and delinquency in adolescents (a type of externalizing behavior). In a 2-year longitudinal study of adolescents by Hopf, Huber, and Weiß (2008), the researchers found a positive relationship between violent video game play and adolescent delinquent behavior. Similarly, cross sectional studies examining undergraduate college students (Anderson \& Dill, 2000) and 12-to-18 old participants found a significant relationship between violent video game play and delinquent behavior (Exelmans, Custers, \& Van den Bulck, 2015). Additionally, the study by Exelmans et al. (2015) found that statistical models including violent video game play were better predictors of delinquent behaviors in adolescents than statistical models only focusing on peer behavior, prior victimization, sensation seeking, and alienation alone. This relationship between violent video game play and delinquent behavior has also been found in clinical populations of institutionalized juvenile delinquents (DeLisi, Vaughn, Gentile, Anderson, \& Shook, 2013). However, Ferguson, Olson, Kutner, and Warner (2014) found that violent video game play was not a significant predictor of delinquent behavior in seventh to eighth graders when parental, peer, and individual characteristics were included in a cross-sectional model. The research findings above are mixed and mostly all obtained through cross-sectional studies using a youth self-report measure of externalizing behavior. As Funk et al. (2002) noted, it is possible that child participants, including aggressive children, had differing perceptions of what constituted higher levels of aggressive and externalizing behavior, a self-report issue that has the potential to account for the disparate findings. Until now, very few longitudinal studies investigating 
this relationship have been conducted, and the ones that exist are relatively short in length. This study will address these gaps by providing longitudinal data about the long-term impact of violent video games on externalizing behavior during adolescence (over 5 years), using data sources from multiple informants.

\section{Video Games and Prosocial Behavior}

Prosocial behavior refers to any voluntary behavior that is intended to help or benefit another individual or group (e.g., sharing, complimenting, helping). Prosocial behavior is associated with many positive outcomes, including life satisfaction, selfacceptance, personal growth, autonomy, positive relationships with others, social coherence, and psychological functioning (Keyes, 2005; Nelson, Layous, Cole, \& Lyubomirsky, 2016). The many positive outcomes of prosocial behavior-both to individuals and to society-underpin the importance of developing and promoting such behavior from an early age.

Several studies have investigated both the short- and long-term effects of violent video games on prosocial behavior. Recent studies have found that in addition to increasing aggressive behavior (Bartholow \& Anderson, 2002), violent video games decrease prosocial behavior in the short and long term (e.g., Anderson et al., 2010). In contrast, video games with prosocial content have been shown to facilitate helping behaviors (see Greitemeyer \& Mügge, 2014 for a review), with increases in empathy acting as a mediator of this relationship (Prot et al., 2014). Specifically, experimental and longitudinal studies have found that prosocial video games increase prosocial thoughts (Greitemeyer \& Osswald, 2010) and promote prosocial behaviors such as altruistic service, defending behaviors, and intervention in harassment situations (Gentile et al., 2009; Greitemeyer \& Osswald, 2010). Given this disparity in outcomes, it is perhaps surprising that violent video game content seems to be much more common than prosocial content in mainstream gaming (Dill et al., 2005; Gentile et al., 2004) and that more-frequent video game users are likely exposed to significantly more violent video game content than prosocial content. For example, Krahé and Möller (2004) found that a higher frequency of game play was positively correlated with the degree to which adolescents recommended violent games. Although it is clearly important to continue to investigate the possible outcomes of playing violent video games, to date, very few studies have examined the long-term impact of violent video games on prosocial behavior. Accordingly, one key aim of the current study is to examine these relationships during adolescence.

\section{Gender}

In examining violent video game play and externalizing behaviors it is important to consider gender. Men have repeatedly been shown to have higher rates of externalizing behaviors starting in early childhood (Miner \& Clarke-Stewart, 2008) and continuing into adulthood (Hicks et al., 2007). Importantly, the trajectories and risk factors of externalizing behaviors differ between men and women (Daigle, Cullen, \& Wright, 2007). Adolescent boys report more serious delinquency than adolescent girls and this may be due to the fact that adolescent boys experience more risk factors and fewer protective factors to delinquency in adolescence than adolescent females (Fagan, Van Horn, Hawkins, \& Arthur, 2007).
Furthermore, adolescent males spend approximately twice as much time playing video games as adolescent females (Greenberg, Sherry, Lachlan, Lucas, \& Holmstrom, 2010) and this disparity in time spent playing video games continues into early adulthood (Ogletree \& Drake, 2007). Particularly important for the current study, adolescent boys are much more likely to play physicallyoriented (aka, violent) video games than adolescent girls (Greenberg et al., 2010). Given the gender differences in violent video game play and externalizing behaviors it is important to consider gender in the current study.

\section{Theoretical Models}

The current study uses the general aggression model (GAM; Anderson \& Bushman, 2002) to explain associations between viewing media, externalizing, and prosocial behaviors. GAM is used primarily as a model to explain the underlying psychological processes during an instance of aggression and prosocial behavior. In short, an environmental trigger interacts with the characteristics (biological and personal) within a person that make them more or less prepared to aggress or behave prosocially. This results in the activation of relevant cognitions and emotions and may also be accompanied by physiological arousal. These cognitions and emotions, in turn, may impel the person toward an aggressive or prosocial action, and this action becomes more likely if the person is quite aroused or doesn't have the time and/or cognitive resources for "reappraisal" processes (i.e., thinking through the consequences of this and alternate responses). Given the similarities and overlap between aggression and the various antisocial behaviors conceptualized as "externalizing," GAM seems to be similarly applicable to externalizing behaviors.

Importantly for this study of effects over time, GAM also proposes mechanisms by which external influences such as violent video games may have a long-term impact on an individual's trait levels of aggression and prosocial behavior, and again, such processes may be relevant to a tendency toward externalizing behavior. Using GAM, viewing aggression in the media may have a long-term impact on these behaviors in a number of ways. First, viewing media aggression may contribute to the formulation, rehearsal, and reinforcement of beliefs and attitudes that normalize externalizing behavior and the construction and reinforcement of knowledge structures in which externalizing behaviors are a key action tendency. Indeed, given that many popular video games (e.g., Grand Theft Auto V) involve and reward a wide range of antisocial behaviors, such processes could be involved in the development, and generalization, of a number of behaviors that could be considered deviant, defiant, disruptive, antisocial, and delinquent (i.e., externalizing). Second, high levels of viewing may emotionally and cognitively desensitize viewers to the suffering of others, including those impacted by externalizing behaviors, thus decreasing barriers to externalizing behavior and the likelihood of prosocial responses such as decreased empathic concern and benevolence for others. This decrease in benevolence and empathic concern after repeated exposure to violent media also decrease the likelihood that a person will respond prosocially. Third, chronic exposure to aggressive or violent video games may lead to a hostile attributional bias that impacts the way others' behavior is perceived and increases the likelihood that innocent behaviors by others will be interpreted as hostile and responded to in a hostile 
way. Fourth, people may imitate the behavior of key media characters who model externalizing behavior, especially if they are admired, high in status, powerful, and/or rewarded for that behavior (e.g., Bandura, 1977). Finally, it is implicit in GAM that external factors such as violent video games may impact a range of internal processes over time to increase an individual's readiness to aggress (Warburton \& Anderson, 2015, 2018). These processes may be biological (e.g., changes to brain function, desensitization) or psychological (e.g., changes to attitudes and beliefs).

Based on predictions from GAM and from existing findings regarding the impact of violent video games on thoughts, feelings, and behavior (e.g., Anderson et al., 2003, 2010), it could be theorized that levels of adolescents' exposure to aggressive media-particularly interactive media such as violent video gameswould predict higher levels of externalizing behavior and lower levels of prosocial behavior over time. The current study tests these hypotheses and also examines three key within-person factors described in GAM that have the potential to change over time and mediate such an effect. These are impaired self-regulation (biological), curtailed empathic concern (psychological), and reduced benevolence (psychological).

\section{Mediators}

Self-regulation. Self-regulation refers to one's ability to modulate thoughts, feelings, and emotions (Posner \& Rothbart, 2000). Self-regulation has been associated with a host of positive outcomes, including improved self-discipline (Duckworth, Grant, Loew, Oettingen, \& Gollwitzer, 2011), goal orientation and attainment (Bouffard, Boisvert, Vezeau, \& Larouche, 1995), and lower levels of delinquent behavior (Tyler, 2009). Self-regulation has also been investigated in association with several media outlets, including TV and Internet usage. While this is a fairly new area of research in the media field, results link low levels of selfregulation to excessive - and, at times, compulsive-media consumption (LaRose, Lin, \& Eastin, 2003). Indeed, Internet gaming disorder, a compulsive use of online games, was added as a mental disorder to the Appendix of the DSM-5 in 2013 and to the body of the ICD-11 in 2017 (Petry et al., 2014). Relevant to this study, neuroimaging studies have linked violent video game play to reduced activity in parts of the brain used in self-regulatory processes such as the prefrontal cortex (Hummer et al., 2010) as well as to reduced cognitive control (Bailey, West, \& Anderson, 2010) and decrements to inhibitory control over time (Hummer, Kronenberger, Wang, \& Mathews, 2017). Self-regulation is also negatively correlated with externalizing behaviors in both children and adolescents (Eisenberg et al., 2001, 2005). In addition to dissuading negative behaviors, it appears that self-regulation facilitates positive social behaviors, including prosocial behavior toward family, friends, and strangers (Padilla-Walker \& Christensen, 2011).

Empathic concern. Empathic concern is a complex human experience involving both top-down and bottom-up cognitive processes and neural networks. It involves perceiving the affective experience of others and responding to that perception using an individual's internal motivations, desires, regulatory abilities, and cognitions. Related emotional responses include sympathy, compassion, and tenderness. It appears that while some forms of media, such as violent video games, decrease empathic concern
(Anderson et al., 2010; Fraser, Padilla-Walker, Coyne, Nelson, \& Stockdale, 2012), prosocial video games (Prot et al., 2014) can increase it. Lower levels of empathic concern have also been linked to antisocial behaviors, including bullying (Gini, Albiero, Benelli, \& Altoè, 2007). Empathic concern has been associated with various aspects of prosocial behavior in children and adolescents as well. It has been found to diminish behavioral problems in children (Hastings, Zahn-Waxler, Robinson, Usher, \& Bridges, 2000) and to motivate altruistic helping intended to minimize suffering in others (Batson, 2010; Coke, Batson, \& McDavis, 1978; Dovidio, Allen, \& Schroeder, 1990), including helping bullied classmates (Gini et al., 2007).

Benevolence. Beliefs and values include internalized principles or standards that govern attitudes and guide behaviors. According to the basic human values theory, benevolence-a value that emphasizes the intrinsic desire to preserve and enhance the welfare of others (Schwartz \& Boehnke, 2004) - is one of many values recognized across cultures. Though benevolence has been studied in many areas, no research to our knowledge exists to investigate the potential relationships between benevolence and different forms of media consumption. There are sound reasons to believe that benevolence may be an important mediating factor in this study. For example, high levels of benevolence have been linked with prosocial behavior (Schwartz, 2010), and lower levels have been associated with higher levels of externalizing behaviors in children (Prinzie et al., 2003; Williams et al., 2009).

\section{Current Study}

The purpose of the current study is to further investigate the relationship between violent video game play and externalizing and prosocial behaviors across a 5-year period in adolescence. In addition to investigating the direct relationship between violent video games and externalizing behaviors, this study will also consider mediators such as self-regulation, empathic concern, and benevolent values, both as outcomes and mediators. We hypothesize that violent video game play during early adolescence will be associated with higher levels of externalizing behavior and lower levels of prosocial behavior in late adolescence. Additionally, we hypothesize that these relationships will be mediated through self-regulation, empathic concern, and a benevolent value system.

\section{Method}

\section{Participants}

The participants for this study were taken from three different years (Waves 3, 5, and 7-referred to as Waves 1, 2, and 3 for reader ease from this point onward) of the Flourishing Families Project (FFP), a longitudinal study of intrafamily life involving 488 families with a child between the ages of 11 and $16(51 \%$ male, $M_{\text {age }}$ of child at Wave $1=13.83, S D=0.98$ ). There was approximately a 2-year gap between measurement periods for each year. Participants were treated in accordance with the American Psychological Association's Code of Conduct, Ethical Principles and Guidelines (American Psychological Association, 2002) and approval for the study was obtained from the Institutional Review Board (IRB) at Brigham Young University for the project entitled "Flourishing Families" (IRB F060311). Just over 67\% of children 
came from two-parent families, while nearly $33 \%$ were in singleparent families $(91 \%$ percent of single parents were mothers and 9\% were fathers). Of the families, 338 were of European American ethnicity, 61 were African American, with smaller numbers for Hispanics (5) and Asian Americans (14). Thirty-eight families are considered multiethnic in nature, based on a combination of two or more ethnic cultures among family members. In terms of parental education, $69.9 \%$ of mothers and approximately $68 \%$ of fathers had a bachelor's degree or higher. For family income, $31.5 \%$ of families reported a yearly income of less than $\$ 59,000$, with $28.3 \%$ reporting income in the $\$ 60,000-99,000$ range, $22.1 \%$ in the $\$ 100,000-139,000$ range, and another $18.1 \%$ making $\$ 140,000$ or more per year.

\section{Procedure}

Participant families for the FFP were primarily recruited using a purchased national telephone survey database (Polk Directories/ InfoUSA). At the time of data collection, this database contained approximately 82 million households across the United States and had detailed information about each household, including presence and age of children. Families identified using the Polk Directory were randomly selected from targeted census tracts that mirrored the socioeconomic and racial stratification reported for local school districts. All families with a child between the ages of 10 and 14 living within target census tracts were deemed eligible to participate in the FFP. Of the 692 eligible families contacted, 423 agreed to participate, resulting in a $61 \%$ response rate. Because the Polk Directory national database was generated using telephone, magazine, and Internet subscription reports, families of lower socioeconomic status were underrepresented in the final sample. In an attempt to more closely mirror the demographics of the local area, a limited number of lower socioeconomic and ethnically diverse families were recruited into the study by other means (e.g., by referrals and fliers). These totaled $n=77$ (15\% of the final sample) and increased the socioeconomic and ethnic diversity of the final sample $(N=500)$. We were able to recontact 488 families for the current study (98\% retention). Finally, there was an $88 \%$ retention rate between the first and last waves measured in the current study. It is important to note that there were very little missing data. As interviewers collected each segment of the inhome interview, questionnaires were screened for missing answers and double marking. Dropout analyses revealed that the data were missing at random. Missing data was handled using the maximum likelihood method in Mplus which allowed us to include participants who had data for at least one wave.

\section{Measures}

All video game and behavioral outcomes were measured at Waves 1 and 3. Mediators were measured at Wave 1 and 2. Multiple reporters of behavior (child, mother, and father) were utilized where data existed and are outlined below.

Video game violence and time (Wave 1 and Wave 3 ). Participants listed their three favorite video games and rated how frequently they played each game on a scale of 1 (not frequently) to 5 (extremely frequently). All the games identified by participants were then distributed to 320 independent raters $\left(58 \%\right.$ male, $\left.M_{\text {age }}=22.50, S D=4.40\right)$, who were asked to rate how much physical aggression was in each game they were familiar with (viewed regularly). Raters were provided with definitions and examples of physical aggression. Ratings were based on a 1 (not physically aggressive) to 5 (extremely physically aggressive) Likert scale. The raters evaluated a total of 97 different games. The mean ratings of all raters for a particular game (at least two raters per game) were determined. Expert ratings are commonly used in media violence research (e.g., Huesmann, Moise-Titus, Podolski, \& Eron, 2003; Krahé, Busching, \& Möller, 2012) and show high reliability, convergent validity, predictive validity, and discriminant validity across multiple cultures and ages (Busching et al., 2015). Intercoder reliability was then assessed with two different methods, consistent with the method set by Huesmann et al. (2003). In particular, we determined the means of the interrater correlations and averaged absolute discrepancies from the mean. Raters with a high number of consistent negative correlations (suggesting lack of care or quality in rating) were omitted. The resulting means and interrater correlations were $z=1.50, r=$ $.90, S D=1.59$. Examples of video games rated as highly aggressive included Grand Theft Auto, Assassin's Creed, and Halo.

A video game violence exposure score was obtained by multiplying content ratings for each game by frequency of game playing, thus giving more weight to games that were played more frequently.

Externalizing behavior (Wave 1 and Wave 3). Externalizing problem behavior was measured using nine delinquency-related items (Barber, Stolz, \& Olsen, 2005) using child, mother, and father reports. Sample items include "I lie or cheat" (or "My child lies or cheats") and "I steal things from places other than home" (or "My child steals things from places other than home"). None of the items measured aggressive behavior. Responses ranged from 0 (not true) to 2 (often true), with higher scores representing higher levels of delinquent/externalizing behavior. There is extensive evidence of both reliability and validity of this measure, and there is evidence that this scale has cross-ethnic equivalence (Krishnakumar, Buehler, \& Barber, 2003). The Cronbach's alpha reliability coefficient for this research sample was found to be acceptable at Wave 1 (child $\alpha=.76$; mother $\alpha=.76$; father $\alpha=.58$ ) and Wave 3 (child $\alpha=.75$; mother $\alpha=.83$; father $\alpha=.80$ ). Child, mother, and father reports of externalizing behavior were used as latent factors at both time points in the analyses below.

Prosocial behavior (Wave 1 and Wave 3). Children's prosocial behavior was measured using nine items based on the Inventory of Strengths (modified from Peterson \& Seligman, 2004). Respondents answered on a 5-point Likert-type scale, ranging from 1 (not like me at all) to 5 (very much like me) in terms of how much they disagreed or agreed with statements about themselves. Sample statements included "I help people I don't know, even if it is not easy for me" and "I go out of my way to cheer up people who seem sad, even if I do not know them." Higher scores indicate greater levels of prosocial behavior. A Cronbach's alpha coefficient of $\alpha=.70$ was found for the original measure (Peterson \& Seligman, 2004), while the Cronbach's alpha reliability coefficients were found to be $\alpha=.83$ for Wave 1 and $\alpha=.85$ at Wave 3.

Self-regulation (Waves 1 and 2). Parents and children reported on the child's ability to regulate emotions, cognitions, and 
behaviors using a 12-item self-regulation measure (revised from Novak \& Clayton, 2001). Parents responded based on how much they agreed or disagreed with statements about their child, such as "My child has difficulty controlling his/her temper," ("I have difficulty controlling my temper") and "My child gets distracted by little things," ("I get distracted by little things"; all examples here were reverse coded). Responses ranged from 1 (never true) to 4 (always true), with higher scores representing the child's ability to regulate his or her emotions, behavior, and cognitions. The Cronbach's alpha reliability coefficient was acceptable at Wave 1 (child $\alpha=.80$; mother $\alpha=.88$; father $\alpha=.87$ ) and Wave 2 (child $\alpha=.81$; mother $\alpha=.88$; father $\alpha=.88$ ). The three reports of self-regulation were used as a latent factor in the analyses reported below.

Empathic concern (Waves 1 and 2). Child's empathic concern was assessed using a 7-item self-report measure from Barber (2002) and based on the measure of Davis (1996). The Likert-type response scale ranged from 1 (strongly disagree) to 5 (strongly agree), and higher scores indicate greater empathic concern for others. Sample items included "I often have tender, concerned feelings for people less fortunate than I" and "When I see someone being taken advantage of, I feel kind of protective towards them." Reliability as reported by Barber (2002) was $\alpha=.72$. The current study also showed acceptable reliability at both Wave $1(\alpha=.76)$ and Wave $2(\alpha=.75)$

Benevolence (Waves 1 and 2). Children's internalized benevolence values were assessed using four items taken from the Portrait Values Questionnaire (Schwartz et al., 2001). Participants rated how much they thought a description of a fictional person was similar to themselves with statements designed to assess respondent benevolence. A 6-point Likert scale was used with response categories ranging from 1 (not like me at all) to 6 (very much like me). Sample items included "Forgiving people who have hurt this person is important to him/her. This person tries to see what is good in them and not to hold a grudge" and "It is important to this person to be loyal to their friends. This person wants to devote himself to people close to him/her." Cronbach's alpha coefficient was found acceptable for Wave $1(\alpha=.80)$ and Wave $2(\alpha=.79)$.

\section{Results}

\section{Preliminary Analyses}

Bivariate correlations between major variables of interest are reported in Table 1. Only child report variables are reported in the table, though bivariate correlations for parents can be viewed in the online supplemental material. At the cross-sectional level, video game violence was negatively correlated with prosocial behavior and positively correlated with externalizing behavior (all at Wave 1). Longitudinally, video game violence (Wave 1) was associated with lower levels of self-regulation (Wave 2), benevolence (Wave 2), empathic concern (Wave 2), and prosocial behavior (Wave 3), and positively associated with externalizing behavior (Wave 3). Additionally, externalizing behavior (Wave 1) was positively and prosocial behavior (Wave 1) was negatively associated with video game violence (Wave 3).

A multivariate analysis of variance was conducted to examine sex differences across the major variables. A multivariate effect of sex of participant was revealed, $F(7,160)=8.62, p<.001$, partial $\eta^{2}=.27$. Means, standard deviations, and univariate effects are reported in Table 2. Boys had significantly higher levels of video game violence exposure (W1 only) than girls, while girls had significantly higher levels of prosocial behavior, empathic concern, and benevolence than boys.

\section{Measurement Model}

A two-group measurement model of externalizing behavior and self-regulation was examined with Mplus (Version 8; Muthén \& Muthén, 1998-2017). Each variable consisted of child, mother, and father reports. The model fit the data acceptably with $\chi^{2}(90)=$ 180.63, $p<.001$, comparative fit index $(\mathrm{CFI})=.96$, TuckerLewis index $(\mathrm{TLI})=.95$, root-mean-square error of approximation $($ RMSEA $)=.06$. All factors loadings were above .40 (Table 3 ). When factor loadings were constrained to be equal across sex and time, the fit did not significantly decrease $\left(\chi^{2}(9)=12.52, p>\right.$ $.05)$, suggesting weak full metric invariance.

Table 1

Bivariate Correlations for Main Variables

\begin{tabular}{|c|c|c|c|c|c|c|c|c|}
\hline Variable name & 1 & 2 & 3 & 4 & 5 & 6 & 7 & 8 \\
\hline \multicolumn{9}{|l|}{ 1. Video game violence (W1) } \\
\hline 2. Prosocial behavior (W1) & $-.18^{* *}$ & & & & & & & \\
\hline 3. Externalizing behavior (W1) & $.24^{* * * *}$ & $-.29^{* * * *}$ & & & & & & \\
\hline 4. Self-regulation (W2) & $-.12^{*}$ & $.21^{* * * *}$ & $-.25^{* * *}$ & & & & & \\
\hline 5. Benevolence (W2) & $-.19^{* *}$ & $.46^{* * * *}$ & $-.22^{* * * *}$ & $.29^{* * * * *}$ & & & & \\
\hline 6. Empathic concern (W2) & $-.26^{* * * *}$ & $.43^{\text {****** }}$ & $-.20^{* * * *}$ & $.09^{*}$ & $.59^{* * * *}$ & & & \\
\hline 7. Video game violence (W3) & $.34^{* * * *}$ & $-.13^{*}$ & $.14^{*}$ & -.08 & $-.16^{*}$ & -.11 & & \\
\hline 8. Prosocial behavior (W3) & $-.18^{* *}$ & $.48^{* * * * *}$ & $-.19^{* * * *}$ & $.21^{* * * *}$ & $.45^{* * * *}$ & $.43^{* *}$ & -.09 & \\
\hline 9. Externalizing behavior (W3) & $.19^{* *}$ & $-.16^{* *}$ & $.42^{* * * *}$ & $-.31^{* * * *}$ & $-.16^{* *}$ & -.09 & .01 & $-.19^{* * * *}$ \\
\hline
\end{tabular}

Note. Wave of data collection is specified in parentheses; all variables in this table represent child report of behaviors. These reporters are used for the purposes of creating the table; however, multiple reporters were used for some variables in the structural equation model, as indicated. See the online supplemental material for additional bivariate correlations. W1 = Wave 1; W2 = Wave 2; W3 = Wave 3.

${ }^{*} p<.05{ }^{* * *} p<.01 .{ }^{* * * *} p<.001$. 
Table 2

Sex Difference for Main Variables

\begin{tabular}{|c|c|c|c|c|c|c|}
\hline \multirow[b]{3}{*}{ Variable } & \multicolumn{4}{|c|}{ Sex of participant } & & \\
\hline & \multicolumn{2}{|c|}{ Male } & \multicolumn{2}{|c|}{ Female } & \multicolumn{2}{|c|}{ MANOVA results } \\
\hline & $M$ & $\overline{S D}$ & $M$ & $\overline{S D}$ & $F$ & $\overline{\text { Partial } \eta^{2}}$ \\
\hline Video game violence exposure (W1) & 8.46 & 4.80 & 4.98 & 3.51 & $23.98^{* * * *}$ & .13 \\
\hline Empathic concern (W2) & 3.61 & .55 & 4.11 & .53 & $32.38^{* * * *}$ & .16 \\
\hline Self-regulation (W2) & 2.82 & .41 & 2.70 & .45 & 2.94 & .02 \\
\hline Benevolence (W2) & 4.50 & .81 & 4.79 & .75 & $5.07^{*}$ & .03 \\
\hline Externalizing behavior (W3) & .35 & .27 & .30 & .26 & 1.33 & .01 \\
\hline Prosocial behavior (W3) & 3.39 & .66 & 3.74 & .65 & $11.20^{\text {**** }}$ & .06 \\
\hline Video game violence exposure (W3) & 8.20 & 4.59 & 7.24 & 5.07 & 1.57 & .01 \\
\hline
\end{tabular}

Note. Child report variables were used for the purpose of the multivariate analysis of variance (MANOVA) for ease of interpretation. Video game violence was examined at Wave 1 (W1), the mediators at Wave 2 (W2), and the outcomes and Wave 3 (W3). Means and $S D$ s for other waves can be obtained by contacting the first author. ${ }^{*} p<.05 .{ }^{* * *} p<.01$.

\section{Structural Model}

A structural equation model was conducted with video game violence at Wave 1 predicting externalizing behavior and prosocial behavior at Wave 3 (controlling for these behaviors at Wave 1). Additionally, video game violence was included at Wave 3 to examine bidirectional associations. Mediators, including empathic concern, self-regulation, and benevolence were modeled at Wave 2. These same mediators were also controlled for at Wave 1 in order to examine whether video game violence resulted in any change in these variables over time. Age was used as a covariate. A multigroup model was conducted to test for structural invariance as a function of sex of participant. The unconstrained model resulted in significantly worse model fit when compared with a fully constrained model. Additionally, each path was examined as a function of gender, with a gender difference emerging only for the path from age to empathy, such that this association was stronger for girls than boys. Accordingly, the model was run as a single group, though gender was included as a covariate.

The final model had an acceptable fit; $\chi^{2}(153)=397.78, p<$ $.001, \mathrm{CFI}=.93, \mathrm{TLI}=.90, \mathrm{RMSEA}=.06$ (Figure 1$)$. There were no significant direct effects between video game violence (Wave 1) and externalizing (Wave $3 ; \beta=.07, p=.242$ ) or prosocial behavior (Wave 3; $\beta=-.06, p=.290$ ) 5 years later. Video game violence (Wave 1) predicted lower levels of empathic concern (Wave 2; $\beta=-.22, p=.001$ ) and benevolence (Wave 2; $\beta=-.14, p=.004)$, though there was no significant effect on self-regulation 2 years later (Wave $2 ; \beta=-.03, p=.459$ ). Finally, empathic concern (Wave $2 ; \beta=.16, p=.01$ ) and benevolence (Wave $2 ; \beta=.18, p=.001$ ) predicted higher levels of prosocial behavior, while lower levels of self-regulation (Wave $2 ; \beta=-.35, p<.001)$ predicted higher levels of externalizing behavior (Wave 3 ). No major variable predicted video game violence exposure at Wave 3, apart from video game violence exposure at Wave $1(\beta=.30, p<.001)$. All other stability paths were highly significant for all variables ( $p<.001$ for all paths).

Indirect effects were estimated using 5,000 bootstrapping samples (using 95\% confidence intervals [CIs]) through the INDIRECT command in Mplus. There were no indirect effects between video game variables and externalizing behavior. However, there was a significant indirect effect between video game violence and later prosocial behavior and benevolence $(\beta=-.03,95 \% \mathrm{CI}[-.05,-.01], p=.048)$ with the indirect effect of empathic concern approaching significance $(\beta=-.04,95 \%$ CI $[-.08,-.01], p=.058)$. Notably, these

Table 3

Factor Loadings for Measurement Model

\begin{tabular}{clcc}
\hline \multicolumn{1}{c}{ Variable } & \multicolumn{1}{c}{ Reporter } & $\begin{array}{c}\text { Factor loadings } \\
\text { for boys }\end{array}$ & $\begin{array}{c}\text { Factor loadings } \\
\text { for girls }\end{array}$ \\
\hline Externalizing behavior (W1) & Mother report & .90 & .92 \\
& Father report & .88 & .88 \\
& Child report & .57 & .67 \\
Externalizing behavior (W3) & Mother report & .91 & .88 \\
& Father report & .86 & .96 \\
Self-regulation (W1) & Child report & .56 & .61 \\
& Mother report & .87 & .80 \\
Self-regulation (W2) & Father report & .81 & .79 \\
& Child report & .47 & .62 \\
& Mother report & .85 & .83 \\
& Father report & .77 & .79 \\
\hline
\end{tabular}

Note. $\mathrm{W} 1=$ Wave $1 ; \mathrm{W} 2=$ Wave $2 ; \mathrm{W} 3=$ Wave 3. 


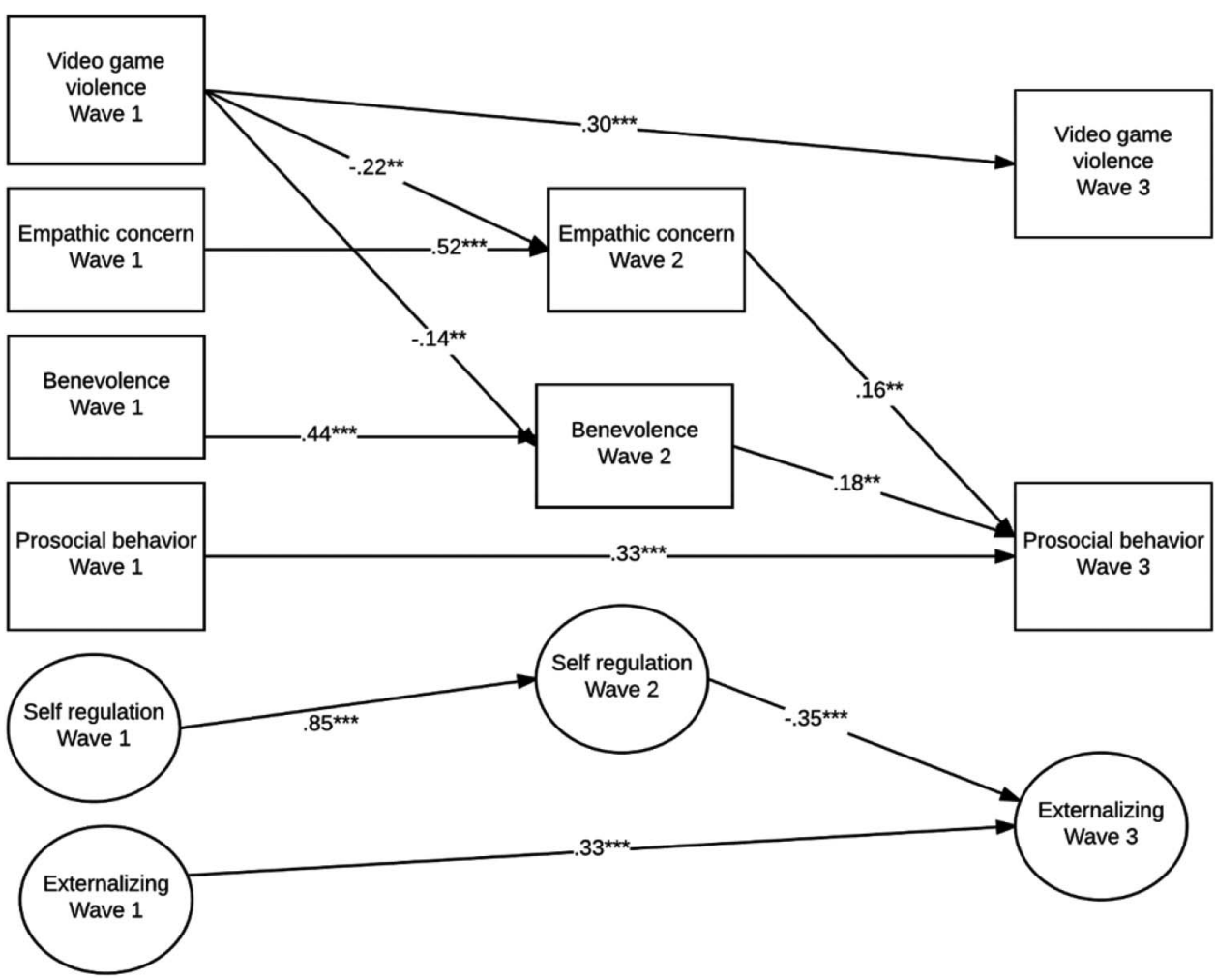

Figure 1. Structural model. Standardized values are shown. For model simplicity, all path weights, factor loadings, and covariances are not shown for exogenous variables (though much of this can be found in the online supplemental material). Control variables are also not shown. Additionally, factor loading, covariances, and error terms for endogenous variables are not shown. Only significant paths are shown in the figure for parsimony, though nonsignificant paths can be viewed in the online supplemental material. ${ }^{* *} p<.01 .{ }^{* * * *} p<.001$.

effects are small in nature, though this should not be surprising given the length of time examined in the current study and the fact that both mediating and outcome variables were all controlled for at the initial time point.

\section{Discussion}

Higher amounts of playing violent video games was related to lower levels of empathic concern and benevolence 2 years later. While there was not a significant direct link between violent video game and prosocial behavior 5 years later, there was a significant indirect association through benevolence.

To our knowledge, this is the first study to show that violent video game play negatively impacts benevolence, ultimately leading to a reduction in prosocial behavior. This finding suggests a higher level change to thinking whereby one's moral orientation toward helping others in need becomes eroded. In a sense, such a finding is not entirely unexpected. While beliefs and attitudes are often somewhat stable, Rokeach (2008) notes that even in adults, human beliefs are still subject to subtle and continual change. For children and, to a lesser extent, adolescents, the development of beliefs and attitudes is more plastic and open to external influence than for adults (White, Hayes, \& Livesy, 2016). Thus, beliefs and attitudes such as benevolence may be somewhat open to downward change when exposed to a steady diet of violent games in a cohort of early to middle adolescents such as the sample tested in this study.

That playing violent games should elicit subtle changes in a belief and attitude such as benevolence would be predicted by several important and well-understood theories. Social-cognitive theory (Bandura, 1986) would predict that substantial and ongoing exposure (real or virtual) to situations where others are hurt rather than helped may lead to attitudes and beliefs that align to those experiences. GAM (Anderson \& Bushman, 2002), which incorporates social-cognitive principles as well as other key learning and schema development theories, would also predict that violent video game exposure has the potential to cause stable changes to attitudes and beliefs, which would then be incorporated into stable knowledge structures and scripts for behavior. Finally, cognitive dissonance theory (e.g., Festinger, 1957) would posit that those who are continually hurting others in one sphere of life (presumably including virtual spheres) would need to align their cognitions, including beliefs and attitudes related to benevolence, to avoid the mental discomfort of cognitive dissonance.

Though exposure to violent video games was concurrently associated with adolescent externalizing behavior, these relationships were not apparent over a 5-year time period. This confirms a number of short-term studies that examine externalizing behavior (e.g., Lohaus et al., 2005), but is not consistent with some of the 
longitudinal research whereby greater violent video game play predicted later measures of aggressive behavior (e.g., Anderson, Gentile, \& Buckley, 2007; Anderson et al., 2008; Gentile, Li, Khoo, Prot, \& Anderson, 2014; Hopf et al., 2008; Krahé et al., 2012; Willoughby, Adachi, \& Good, 2012) and trait aggression (Lemmens, Valkenburg, \& Peter, 2011; Möller \& Krahé, 2009). However, other researchers have failed to find an association between violent video game play and increased aggressive behavior. Ferguson et al. (2008) found family violence exposure and trait aggression to be significant predictors of violent criminality, but not violent video game play. Indeed, a meta-analytic study, adjusting for a theoretical publication bias in media violence research, suggested that playing violent video games was not associated with increased aggression in the lab or in real life (Ferguson, 2007). While the majority of research suggests an association between engaging with violent media and increased aggressive behavior, more work is needed to understand for who, when, and under what circumstances exposure to violent media is related to increased aggressive behavior. It may be that violent video games have a larger impact on externalizing behavior in the short term, and have little impact over the long term, at least with this sample.

Exposure to violent video games was also related to lower levels of empathic concern 2 years later, which was then associated with lower prosocial behavior. Empathic concern did not mediate the relationship between violence video game play and prosocial behavior, though it was in the hypothesized prediction and nearing significance ( $p=.058$ ). Chronic exposure to violent video games may be related to changes in emotional processing, and this seems to be particularly true for people with higher or lower levels of empathic concern (Stockdale, Morrison, Palumbo, Garbarino, \& Silton, 2017). The current study adds to a growing literature showing an association between playing violent video games and lower levels of future empathic concern, however, more work is needed to disentangle the direction of effects and the variability in the relationships between violent video game play and empathic concern (Prot et al., 2014).

Additionally, playing violent video games was not related to changes in self-regulation across time. This finding is at odds with other research suggesting that playing video games may be related to constructs linked to self-regulation, including self-control deficits (Gabbiadini, Riva, Andrighetto, Volpato, \& Bushman, 2014), impulsivity (Lin \& Lepper, 1987), and attention deficits (Swing, Gentile, Anderson, \& Walsh, 2010). It is also inconsistent with research showing that adolescents with poor self-regulatory abilities are more likely to spend excessive time using media (LaRose et al., 2003). This may be a result of the high stability of selfregulation over time in our model. Indeed, exposure to violent video games was associated with poor self-regulation at the crosssectional level, however, such exposure doesn't appear to decrease self-regulation over time when previous levels of self-regulation are taken into account. Such research is scarce, particularly within longitudinal designs, and research that uses a wider array of self-regulation measures is needed.

Likewise, self-regulation is a broad cognitive construct including components of executive functions, behavioral and motor control, and emotional regulation. Perhaps an omnibus measure of self-regulation, such as the measure used in the present study, cannot adequately capture the nuanced changes in cognitive constructs underlying self-regulation that may be modulated by expo- sure to violent video games. For example, in a series of studies playing violent video games was related to changes in orienting and processing of emotional information, but differences emerged when the emotional information was relevant or irrelevant to the task at hand, suggesting that the effect of violent video game play on executive functioning and cognitive control may be dependent on if the executive functioning and control is in the presence of emotionally salient information (Bailey, West, \& Anderson, 2011). Also, frequent and infrequent players of video games were asked to complete a Stroop task. Differences emerged between the two groups regarding proactive versus reactive control, with frequent players displaying poorer reactive control, but no difference in proactive control (Bailey et al., 2010), again suggesting the importance of taking a more nuanced approach to investigating the effects of violent video game play on executive functioning, selfregulation, and cognitive control. Finally, Swing and Anderson (2014) found that impulsivity and attention problems mediated the relationship between media violence exposure and aggressive behavior, but this mediation differed when examining reactive versus proactive aggressive behavior, suggesting that it is also important to take a more nuanced approach to externalizing behaviors when examining the mediating roles of regulatory behaviors in media violence exposure and externalizing behaviors.

The present study adds to emerging knowledge about the longitudinal associations of violent video game play on externalizing behaviors and prosocial behaviors; however, it is not without limitations. Although the current study obtained multiple reports for externalizing behavior, self-regulation, and game ratings, selfreport measures were used for some other study outcomes. While adolescents are fairly accurate reporters of their own behaviors and are typically good reporters of their own media use and the content of the media they use (Gentile et al., 2009), the shortcomings of self-report data are well documented. Future researchers could expand the current study by employing observational measures and multiple-informant measures of all key factors. Additionally, the design of the current study cannot speak to the causality of early exposure to video game violence and later beliefs and outcomes.

Within the noted limitations, the current study points to a longitudinal association of playing violent video games on prosocial behavior in adolescents, specifically by subscribing to a less benevolent value system over time. Importantly, these associations were found even while controlling for these variables at the initial time point. Notably, though playing violent videos games was associated with concurrent levels of externalizing behavior, there was little evidence of a long-term effect in the current sample. Parents, educators, policymakers, and consumers are thus encouraged to take into account the potential outcomes of consuming video games with violent content.

\section{References}

American Psychological Association. (2002). Ethical principles of psychologists and code of conduct. American Psychologist, 57, 1060-1073.

Anderson, C. A., Berkowitz, L., Donnerstein, E., Huesmann, L. R., Johnson, J. D., Linz, D., . . . Wartella, E. (2003). The influence of media violence on youth. Psychological Science in the Public Interest, 4, 81-110. http://dx.doi.org/10.1111/j.1529-1006.2003.pspi_1433.x

Anderson, C. A., \& Bushman, B. J. (2001). Effects of violent video games on aggressive behavior, aggressive cognition, aggressive affect, physi- 
ological arousal, and prosocial behavior: A meta-analytic review of the scientific literature. Psychological Science, 12, 353-359. http://dx.doi .org/10.1111/1467-9280.00366

Anderson, C. A., \& Bushman, B. J. (2002). Psychology. The effects of media violence on society. Science, 295, 2377-2379. http://dx.doi.org/ 10.1126/science. 1070765

Anderson, C. A., Bushman, B. J., Donnerstein, E., Hummer, T. A., \& Warburton, W. A. (2015). SPSSI research summary on media violence. Analyses of Social Issues and Public Policy, 15, 4-19. http://dx.doi.org/ 10.1111/asap. 12093

Anderson, C. A., \& Dill, K. E. (2000). Video games and aggressive thoughts, feelings, and behavior in the laboratory and in life. Journal of Personality and Social Psychology, 78, 772-790. http://dx.doi.org/10 $.1037 / 0022-3514.78 .4 .772$

Anderson, C. A., Gentile, D. A., \& Buckley, K. E. (2007). Violent video game effects on children and adolescents: Theory, research, and public policy. New York, NY: Oxford University Press. http://dx.doi.org/10 .1093/acprof:oso/9780195309836.001.0001

Anderson, C. A., Sakamoto, A., Gentile, D. A., Ihori, N., Shibuya, A., Yukawa, S., . . Kobayashi, K. (2008). Longitudinal effects of violent video games on aggression in Japan and the United States. Pediatrics, 122, e1067-e1072. http://dx.doi.org/10.1542/peds.2008-1425

Anderson, C. A., Shibuya, A., Ihori, N., Swing, E. L., Bushman, B. J., Sakamoto, A., . . . Saleem, M. (2010). Violent video game effects on aggression, empathy, and prosocial behavior in eastern and western countries: A meta-analytic review. Psychological Bulletin, 136, 151173. http://dx.doi.org/10.1037/a0018251

Anderson, C. A., Suzuki, K., Swing, E. L., Groves, C. L., Gentile, D. A., Prot, S., . . . Petrescu, P. (2017). Media violence and other aggression risk factors in seven nations. Personality and Social Psychology Bulletin, 43, 986-998. http://dx.doi.org/10.1177/0146167217703064

Anderson, C. A., \& Warburton, W. A. (2012). The impact of violent video games: An overview. In W. A. Warburton \& D. Braunstein (Eds.), Growing up fast and furious: Reviewing the impacts of violent and sexualised media on children (pp. 56-84). Sydney, New South Wales, Australia: The Federation Press.

Bailey, K., West, R., \& Anderson, C. A. (2010). A negative association between video game experience and proactive cognitive control. Psychophysiology, 47, 34-42. http://dx.doi.org/10.1111/j.1469-8986.2009 .00925.x

Bailey, K., West, R., \& Anderson, C. A. (2011). The association between chronic exposure to video game violence and affective picture processing: An ERP study. Cognitive, Affective \& Behavioral Neuroscience, 11, 259-276. http://dx.doi.org/10.3758/s13415-011-0029-y

Bandura, A. (1977). Social learning theory. Englewood Cliffs, NJ: Prentice Hall.

Bandura, A. (1986). Social foundations of thought and action: A social cognitive theory. Englewood Cliffs, NJ: Prentice Hall.

Barber, B. K. (2002). Positive interpersonal and intrapersonal functioning: An assessment of measures among adolescents. In K. A. Moore \& L. H. Lippman (Eds.), What do children need to flourish? (pp. 147-161). New York, NY: Springer.

Barber, B. K., Stolz, H. E., \& Olsen, J. A. (2005). Parental support, psychological control, and behavioral control: Assessing relevance across time, culture, and method. Monographs of the Society for Research in Child Development, 70, 1-137.

Bartholow, B. D., \& Anderson, C. A. (2002). Effects of violent video games on aggressive behavior: Potential sex differences. Journal of Experimental Social Psychology, 38, 283-290. http://dx.doi.org/10 $.1006 /$ jesp.2001.1502

Bartholow, B. D., Bushman, B. J., \& Sestir, M. A. (2006). Chronic violent video game exposure and desensitization to violence: Behavioral and event-related brain potential data. Journal of Experimental Social Psychology, 42, 532-539. http://dx.doi.org/10.1016/j.jesp.2005.08.006
Batson, C. D. (2010). Empathy-induced altruistic motivation. In M. Mikulincer, P. R. Shaver, M. Mikulincer, \& P. R. Shaver (Eds.), Prosocial motives, emotions, and behavior: The better angels of our nature (pp. 15-34). Washington, DC: American Psychological Association. http:// dx.doi.org/10.1037/12061-001

Bouffard, T., Boisvert, J., Vezeau, C., \& Larouche, C. (1995). The impact of goal orientation on self-regulation and performance among college students. British Journal of Educational Psychology, 65, 317-329. http://dx.doi.org/10.1111/j.2044-8279.1995.tb01152.x

Bryant, J., \& Oliver, M. B. (Eds.). (2009). Media effects: Advances in theory and research. New York, NY: Routledge.

Busching, R., Gentile, D. A., Krahé, B., Möller, I., Khoo, A., Walsh, D. A., \& Anderson, C. A. (2015). Testing the reliability and validity of different measures of violent video game use in the United States, Singapore, and Germany. Psychology of Popular Media Culture, 4, 97-111. http:// dx.doi.org/10.1037/ppm0000004

Campbell, S. B., Shaw, D. S., \& Gilliom, M. (2000). Early externalizing behavior problems: Toddlers and preschoolers at risk for later maladjustment. Development and Psychopathology, 12, 467-488. http://dx.doi .org/10.1017/S0954579400003114

Carnagey, N. L., Anderson, C. A., \& Bushman, B. J. (2007). The effect of video game violence on physiological desensitization to real-life violence. Journal of Experimental Social Psychology, 43, 489-496. http:// dx.doi.org/10.1016/j.jesp.2006.05.003

Children Now. (2001). Fair play? Violence, gender and race in video games. Los Angeles, CA: Author.

Coke, J. S., Batson, C. D., \& McDavis, K. (1978). Empathic mediation of helping: A two stage model. Journal of Personality and Social Psychology, 36, 752-766. http://dx.doi.org/10.1037/0022-3514.36.7.752

Daigle, L. E., Cullen, F. T., \& Wright, J. P. (2007). Gender differences in the predictors of juvenile delinquency: Assessing the generalityspecificity debate. Youth Violence and Juvenile Justice, 5, 254-286. http://dx.doi.org/10.1177/1541204007301289

Davis, M. H. (1996). Empathy: A social-psychological approach. Boulder, CO: Westview Press.

DeCamp, W., \& Ferguson, C. J. (2017). The impact of degree of exposure to violent video games, family background, and other factors on youth violence. Journal of Youth and Adolescence, 46, 388-400. http://dx.doi .org/10.1007/s10964-016-0561-8

DeLisi, M., Vaughn, M. G., Gentile, D. A., Anderson, C. A., \& Shook, J. J (2013). Violent video games, delinquency, and youth violence: New evidence. Youth Violence and Juvenile Justice, 11, 132-142. http://dx doi.org/10.1177/1541204012460874

Dill, K. E., Gentile, D. A., Richter, W. A., \& Dill, J. C. (2005). Violence, sex, race and age in popular video games: A content analysis. In E. Cole \& D. J. Henderson (Eds.), Featuring females: Feminist analyses of the media (pp. 115-130). Washington, DC: American Psychological Association. http://dx.doi.org/10.1037/11213-008

Dovidio, J. F., Allen, J. L., \& Schroeder, D. A. (1990). The specificity of empathy-induced helping: Evidence for altruistic motivation. Journal of Personality and Social Psychology, 59, 249-260. http://dx.doi.org/10 1037/0022-3514.59.2.249

Downs, E., \& Smith, S. L. (2010). Keeping abreast of hypersexuality: A video game character content analysis. Sex Roles, 62, 721-733. http:// dx.doi.org/10.1007/s11199-009-9637-1

Duckworth, A. L., Grant, H., Loew, B., Oettingen, G., \& Gollwitzer, P. M (2011). Self-regulation strategies improve self-discipline in adolescents: Benefits of mental contrasting and implementation intentions. Educational Psychology, 31, 17-26. http://dx.doi.org/10.1080/01443410.2010 .506003

Eisenberg, N., Cumberland, A., Spinrad, T. L., Fabes, R. A., Shepard, S. A., Reiser, M., . . Guthrie, I. K. (2001). The relations of regulation and emotionality to children's externalizing and internalizing problem 
behavior. Child Development, 72, 1112-1134. http://dx.doi.org/10.1111/ 1467-8624.00337

Eisenberg, N., Zhou, Q., Spinrad, T. L., Valiente, C., Fabes, R. A., \& Liew, J. (2005). Relations among positive parenting, children's effortful control, and externalizing problems: A three-wave longitudinal study. Child Development, 76, 1055-1071. http://dx.doi.org/10.1111/j.1467-8624 .2005.00897.x

Escobar-Chaves, S. L., Tortolero, S. R., Markham, C. M., Low, B. J., Eitel, P., \& Thickstun, P. (2005). Impact of the media on adolescent sexual attitudes and behaviors. Pediatrics, 116, 303-326.

Exelmans, L., Custers, K., \& Van den Bulck, J. (2015). Violent video games and delinquent behavior in adolescents: A risk factor perspective. Aggressive Behavior, 41, 267-279. http://dx.doi.org/10.1002/ab.21587

Fagan, A. A., Van Horn, M. L., Hawkins, J. D., \& Arthur, M. W. (2007). Gender similarities and differences in the association between risk and protective factors and self-reported serious delinquency. Prevention Science, 8, 115-124. http://dx.doi.org/10.1007/s11121-006-0062-1

Ferguson, C. J. (2007). The good, the bad and the ugly: A meta-analytic review of positive and negative effects of violent video games. Psychiatric Quarterly, 78, 309-316. http://dx.doi.org/10.1007/s11126-0079056-9

Ferguson, C. J., Olson, C. K., Kutner, L. A., \& Warner, D. E. (2014). Violent video games, catharsis seeking, bullying, and delinquency: A multivariate analysis of effects. Crime \& Delinquency, 60, 764-784. http://dx.doi.org/10.1177/0011128710362201

Ferguson, C. J., Rueda, S. M., Cruz, A. M., Ferguson, D. E., Fritz, S., \& Smith, S. M. (2008). Violent video games and aggression: Causal relationship or byproduct of family violence and intrinsic violence motivation? Criminal Justice and Behavior, 35, 311-332.

Festinger, L. (1957). A theory of cognitive dissonance. Evanston, IL: Row Peterson.

Fraser, A. M., Padilla-Walker, L. M., Coyne, S. M., Nelson, L. J., \& Stockdale, L. A. (2012). Associations between violent video gaming, empathic concern, and prosocial behavior toward strangers, friends, and family members. Journal of Youth and Adolescence, 41, 636-649. http://dx.doi.org/10.1007/s10964-012-9742-2

Funk, J. B., Hagan, J., Schimming, J., Bullock, W. A., Buchman, D. D., \& Myers, M. (2002). Aggression and psychopathology in adolescents with a preference for violent electronic games. Aggressive Behavior, 28, 134-144. http://dx.doi.org/10.1002/ab.90015

Gabbiadini, A., Riva, P., Andrighetto, L., Volpato, C., \& Bushman, B. J. (2014). Interactive effect of moral disengagement and violent video games on self-control, cheating, and aggression. Social Psychological and Personality Science, 5, 451-458. http://dx.doi.org/10.1177/ 1948550613509286

Gentile, D. A., Anderson, C. A., Yukawa, S., Ihori, N., Saleem, M., Ming, L. K., ... Sakamoto, A. (2009). The effects of prosocial video games on prosocial behaviors: International evidence from correlational, longitudinal, and experimental studies. Personality and Social Psychology Bulletin, 35, 752-763. http://dx.doi.org/10.1177/0146167209333045

Gentile, D. A., Li, D., Khoo, A., Prot, S., \& Anderson, C. A. (2014). Mediators and moderators of long-term effects of violent video games on aggressive behavior: Practice, thinking, and action. Journal of the American Medical Association Pediatrics, 168, 450-457. http://dx.doi .org/10.1001/jamapediatrics.2014.63

Gentile, D. A., Lynch, P. J., Linder, J. R., \& Walsh, D. A. (2004). The effects of violent video game habits on adolescent hostility, aggressive behaviors, and school performance. Journal of Adolescence, 27, 5-22. http://dx.doi.org/10.1016/j.adolescence.2003.10.002

Gentile, D. A., Swing, E. L., Anderson, C. A., Rinker, D., \& Thomas, K. H. (2016). Differential neural recruitment during violent video game play in violent- and nonviolent-game players. Psychology of Popular Media Culture, 5, 39-51. http://dx.doi.org/10.1037/ppm0000009
Gini, G., Albiero, P., Benelli, B., \& Altoè, G. (2007). Does empathy predict adolescents' bullying and defending behavior? Aggressive Behavior, 33, 467-476. http://dx.doi.org/10.1002/ab.20204

Green, C. S., \& Bavelier, D. (2006). Effect of action video games on the spatial distribution of visuospatial attention. Journal of Experimental Psychology: Human Perception and Performance, 32, 1465-1478. http://dx.doi.org/10.1037/0096-1523.32.6.1465

Greenberg, B. S., Sherry, J., Lachlan, K., Lucas, K., \& Holmstrom, A. (2010). Orientations to video games among gender and age groups. Simulation \& Gaming, 41, 238-259. http://dx.doi.org/10.1177/ 1046878108319930

Greitemeyer, T., \& Mügge, D. O. (2014). Video games do affect social outcomes: A meta-analytic review of the effects of violent and prosocial video game play. Personality and Social Psychology Bulletin, 40, 578 589. http://dx.doi.org/10.1177/0146167213520459

Greitemeyer, T., \& Osswald, S. (2010). Effects of prosocial video games on prosocial behavior. Journal of Personality and Social Psychology, 98 211-221. http://dx.doi.org/10.1037/a0016997

Hastings, P. D., Zahn-Waxler, C., Robinson, J., Usher, B., \& Bridges, D. (2000). The development of concern for others in children with behavior problems. Developmental Psychology, 36, 531-546. http://dx.doi.org/10 .1037/0012-1649.36.5.531

Hicks, B. M., Blonigen, D. M., Kramer, M. D., Krueger, R. F., Patrick, C. J., Iacono, W. G., \& McGue, M. (2007). Gender differences and developmental change in externalizing disorders from late adolescence to early adulthood: A longitudinal twin study. Journal of Abnormal Psychology, 116, 433-447. http://dx.doi.org/10.1037/0021-843X.116.3 .433

Holtz, P., \& Appel, M. (2011). Internet use and video gaming predict problem behavior in early adolescence. Journal of Adolescence, 34, 49-58. http://dx.doi.org/10.1016/j.adolescence.2010.02.004

Hopf, W. H., Huber, G. L., \& Weiß, R. H. (2008). Media violence and youth violence: A 2-year longitudinal study. Journal of Media Psychology: Theories, Methods, and Applications, 20, 79-96. http://dx.doi.org/ 10.1027/1864-1105.20.3.79

Huesmann, L. R., Moise-Titus, J., Podolski, C. L., \& Eron, L. D. (2003). Longitudinal relations between children's exposure to TV violence and their aggressive and violent behavior in young adulthood: 1977-1992. Developmental Psychology, 39, 201-221. http://dx.doi.org/10.1037/ 0012-1649.39.2.201

Hummer, T. A., Kronenberger, W. G., Wang, Y., \& Mathews, V. P. (2017). Decreased prefrontal activity during a cognitive inhibition task following violent video game play: A multi-week randomized trial. Psychology of Popular Media Culture. Advance online publication. http://dx.doi .org/10.1037/ppm0000141

Hummer, T. A., Wang, Y., Kronenberger, W. G., Mosier, K. M., Kalnin, A. J., Dunn, D. W., \& Mathews, V. P. (2010). Short-term violent video game play by adolescents alters prefrontal activity during cognitive inhibition. Media Psychology, 13, 136-154. http://dx.doi.org/10.1080/ 15213261003799854

Keyes, C. L. M. (2005). Chronic physical conditions and aging: Is mental health a potential protective factor? Ageing International, 30, 88-104. http://dx.doi.org/10.1007/BF02681008

Klein, J. D., Brown, J. D., Childers, K. W., Oliveri, J., Porter, C., \& Dykers, C. (1993). Adolescents' risky behavior and mass media use. Pediatrics, 92, 24-31.

Konijn, E. A., Bijvank, M. N., \& Bushman, B. J. (2007). I wish I were a warrior: The role of wishful identification in the effects of violent video games on aggression in adolescent boys. Developmental Psychology, 43, 1038-1044. http://dx.doi.org/10.1037/0012-1649.43.4.1038

Krahé, B., Busching, R., \& Möller, I. (2012). Media violence use and aggression among German adolescents: Associations and trajectories of change in a three-wave longitudinal study. Psychology of Popular Media Culture, 1, 152-166. http://dx.doi.org/10.1037/a0028663 
Krahé, B., \& Möller, I. (2004). Playing violent electronic games, hostile attributional style, and aggression-related norms in German adolescents. Journal of Adolescence, 27, 53-69. http://dx.doi.org/10.1016/j .adolescence.2003.10.006

Krishnakumar, A., Buehler, C., \& Barber, B. K. (2003). Youth perceptions of interparental conflict, ineffective parenting, and youth problem behaviors in European-American and African-American families. Journal of Social and Personal Relationships, 20, 239-260. http://dx.doi.org/10 $.1177 / 02654075030202007$

LaRose, R., Lin, C. A., \& Eastin, M. S. (2003). Unregulated Internet usage: Addiction, habit, or deficient self-regulation? Media Psychology, 5, 225-253. http://dx.doi.org/10.1207/S1532785XMEP0503_01

Lemmens, J. S., Valkenburg, P. M., \& Peter, J. (2011). The effects of pathological gaming on aggressive behavior. Journal of Youth and Adolescence, 40, 38-47. http://dx.doi.org/10.1007/s10964-010-9558-x

Lin, S., \& Lepper, M. R. (1987). Correlates of children's usage of videogames and computers. Journal of Applied Social Psychology, 17, 72-93. http://dx.doi.org/10.1111/j.1559-1816.1987.tb00293.x

Lohaus, A., Ball, J., Klein-Hessling, J., \& Wild, M. (2005). Relations between media use and self-reported symptomatology in young adolescents. Anxiety, Stress \& Coping: An International Journal, 18, 333-341. http://dx.doi.org/10.1080/10615800500258123

Markey, P. M., \& Ferguson, C. J. (2017). Moral combat: Why the war on violent video games is wrong. Dallas, TX: BenBella Books.

Maughan, D. R., Christiansen, E., Jenson, W. R., Olympia, D., \& Clark, E. (2005). Behavioral parent training as a treatment for externalizing behaviors and disruptive behavior disorders: A meta-analysis. School Psychology Review, 34, 267-286.

Media Violence Commission, International Society for Research on Aggression. (2012). Report of the Media Violence Commission. Aggressive Behavior, 38, 335-341. http://dx.doi.org/10.1002/ab.21443

Miner, J. L., \& Clarke-Stewart, K. A. (2008). Trajectories of externalizing behavior from age 2 to age 9: Relations with gender, temperament, ethnicity, parenting, and rater. Developmental Psychology, 44, 771-786. http://dx.doi.org/10.1037/0012-1649.44.3.771

Möller, I., \& Krahé, B. (2009). Exposure to violent video games and aggression in German adolescents: A longitudinal analysis. Aggressive Behavior, 35, 75-89. http://dx.doi.org/10.1002/ab.20290

Muthén, L. K., \& Muthén, B. O. (1998-2017). Mplus user's guide (8th ed.). Los Angeles, CA: Author.

Nelson, S. K., Layous, K., Cole, S. W., \& Lyubomirsky, S. (2016). Do unto others or treat yourself? The effects of prosocial and self-focused behavior on psychological flourishing. Emotion, 16, 850-861. http://dx .doi.org/10.1037/emo0000178

Novak, S. P., \& Clayton, R. R. (2001). The influence of school environment and self-regulation on transitions between stages of cigarette smoking: A multilevel analysis. Health Psychology, 20, 196-207. http:// dx.doi.org/10.1037/0278-6133.20.3.196

Ogletree, S. M., \& Drake, R. (2007). College students' video game participation and perceptions: Gender differences and implications. Sex Roles, 56, 537-542. http://dx.doi.org/10.1007/s11199-007-9193-5

Padilla-Walker, L. M., \& Christensen, K. J. (2011). Empathy and selfregulation as mediators between parenting and adolescents' prosocial behavior toward strangers, friends, and family. Journal of Research on Adolescence, 21, 545-551. http://dx.doi.org/10.1111/j.1532-7795.2010 .00695.x

Padilla-Walker, L. M., Nelson, L. J., Carroll, J. S., \& Jensen, A. C. (2010). More than a just a game: Video game and internet use during emerging adulthood. Journal of Youth and Adolescence, 39, 103-113. http://dx .doi.org/10.1007/s10964-008-9390-8

Pardun, C. J., L'Engle, K. L., \& Brown, J. D. (2005). Linking exposure to outcomes: Early adolescents' consumption of sexual content in six media. Mass Communication \& Society, 8, 75-91. http://dx.doi.org/10 .1207/s15327825mcs0802_1
Peterson, C., \& Seligman, M. E. P. (2004). Character strengths and virtues: A handbook and classification. New York, NY: Oxford University Press.

Petry, N. M., Rehbein, F., Gentile, D. A., Lemmens, J. S., Rumpf, H. J., Mößle, T., . . . O'Brien, C. P. (2014). An international consensus for assessing internet gaming disorder using the new DSM-5 approach. Addiction, 109, 1399-1406. http://dx.doi.org/10.1111/add.12457

Posner, M. I., \& Rothbart, M. K. (2000). Developing mechanisms of self-regulation. Development and Psychopathology, 12, 427-441. http:// dx.doi.org/10.1017/S0954579400003096

Prinzie, P., Onghena, P., Hellinckx, W., Grietens, H., Ghesquiere, P., \& Colpin, H. (2003). The additive and interactive effects of parenting and children's personality on externalizing behaviour. European Journal of Personality, 17, 95-117. http://dx.doi.org/10.1002/per.467

Prot, S., Gentile, D. A., Anderson, C. A., Suzuki, K., Swing, E., Lim, K. M., . . Lam, B. C. P. (2014). Long-term relations among prosocialmedia use, empathy, and prosocial behavior. Psychological Science, 25, 358-368. http://dx.doi.org/10.1177/0956797613503854

Rey, J. M., \& Morris-Yates, A. (1993). Are oppositional and conduct disorders of adolescents separate conditions? Australian and New Zealand Journal of Psychiatry, 27, 281-287. http://dx.doi.org/10.1080/ 00048679309075778

Rideout, V. J. (2015). The common sense census: Media use by teens and tweens. San Francisco, CA: Common Sense Media.

Robinson, T. N., Chen, H. L., \& Killen, J. D. (1998). Television and music video exposure and risk of adolescent alcohol use. Pediatrics, 102, e54 http://dx.doi.org/10.1542/peds.102.5.e54

Roe, K. (1996). Music and identity among European youth: Music as communication. In P. Rutten (Ed.), Music in Europe (pp. 85-97). Brussels, Belgium: European Music Office.

Rokeach, M. (2008). Understanding human values: Individual and societal New York, NY: The Free Press.

Schmidt, M., \& Anderson, D. (2007). The impact of television on cognitive development and educational achievement. In N. Pecora, D. Murray, \& E. Wartella (Eds.), Children and television: Fifty years of research (pp. 65-84). Mahwah, NJ: Erlbaum.

Schwartz, S. H. (2010). Basic values: How they motivate and inhibit prosocial behavior. In M. Mikulincer \& P. R. Shaver (Eds.), Prosocial motives, emotions, and behavior: The better angels of our nature ( $\mathrm{pp}$ 221-241). Washington, DC: American Psychological Association.

Schwartz, S. H., \& Boehnke, K. (2004). Evaluating the structure of human values with confirmatory factor analysis. Journal of Research in Personality, 38, 230-255. http://dx.doi.org/10.1016/S0092-6566(03) 00069-2

Schwartz, S. H., Melech, G., Lehmann, A., Burgess, S., Harris, M., \& Owens, V. (2001). Extending the cross-cultural validity of the theory of basic human values with a different method of measurement. Journal of Cross-Cultural Psychology, 32, 519-542. http://dx.doi.org/10.1177/ 0022022101032005001

Stockdale, L., Morrison, R. G., Palumbo, R., Garbarino, J., \& Silton, R. L. (2017). Cool, callous and in control: Superior inhibitory control in frequent players of video games with violent content. Social Cognitive and Affective Neuroscience, 12, 1869-1880.

Swing, E. L., \& Anderson, C. A. (2014). The role of attention problems and impulsiveness in media violence effects on aggression. Aggressive Behavior, 40, 197-203. http://dx.doi.org/10.1002/ab.21519

Swing, E. L., Gentile, D. A., Anderson, C. A., \& Walsh, D. A. (2010) Television and video game exposure and the development of attention problems. Pediatrics, 126, 214-221. http://dx.doi.org/10.1542/peds .2009-1508

Tackett, J. L., Krueger, R. F., Sawyer, M. G., \& Graetz, B. W. (2003). Subfactors of $D S M-I V$ conduct disorder: Evidence and connections with syndromes from the Child Behavior Checklist. Journal of Abnormal 
Child Psychology, 31, 647-654. http://dx.doi.org/10.1023/A: 1026214324287

Tyler, T. R. (2009). Legitimacy and criminal justice: The benefits of self-regulation. Ohio State Journal of Criminal Law, 7, 307-359.

Walsh, D., Gentile, D. A., Gieske, J., Walsh, M., \& Chasco, E. (2003). MediaWise video game report card. Minneapolis, MN: National Institute on Media and the Family.

Warburton, W. A. (2012). Growing up fast and furious in a media saturated world. In W. A. Warburton \& D. Braunstein (Eds.), Growing up fast and furious: Reviewing the impacts of violent and sexualised media on children (pp. 1-33). Sydney, New South Wales, Australia: The Federation Press.

Warburton, W. A. (2014). Apples, oranges and the burden of proof: Putting media violence findings in context. European Psychologist, 19, 60-67. http://dx.doi.org/10.1027/1016-9040/a000166

Warburton, W. A., \& Anderson, C. A. (2015). Social psychological study of aggression. In J. Wright (Ed.), International encyclopaedia of social and behavioral sciences (2nd ed., pp. 295-299). Oxford, UK: Elsevier.

Warburton, W. A., \& Anderson, C. A. (in press). Aggression. In T. K. Shackleford \& P. Zeigler-Hill (Eds.), The SAGE handbook of personality and individual differences. Thousand Oaks CA: Sage.

Warburton, W. A., \& Anderson, C. A. (2018). Aggression. In V. ZeiglerHill \& T. K. Shackelford (Eds.), The SAGE handbook of personality and individual differences (pp. 183-211). Thousand Oaks, CA: Sage.
Warburton, W. A., \& Braunstein, D. (Eds.). (2012). Growing up fast and furious: Reviewing the impact of violent and sexualised media on children. Sydney, New South Wales, Australia: The Federation Press.

Warburton, W. A., \& Highfield, K. (2016). Children and technology in a smart device world. In R. Grace, K. Hodge, \& C. McMahon (Eds.), Children, families and communities: Contexts and consequences (5th ed., pp. 195-221). New York, NY: Oxford University Press.

White, F., Hayes, B., \& Livesy, D. (2016). Developmental psychology: From infancy to adulthood (4th ed.). Melbourne, Victoria, Australia: Pearson.

Williams, L. R., Degnan, K. A., Perez-Edgar, K. E., Henderson, H. A., Rubin, K. H., Pine, D. S., . . Fox, N. A. (2009). Impact of behavioral inhibition and parenting style on internalizing and externalizing problems from early childhood through adolescence. Journal of Abnormal Child Psychology, 37, 1063-1075. http://dx.doi.org/10.1007/s10802009-9331-3

Willoughby, T., Adachi, P. J., \& Good, M. (2012). A longitudinal study of the association between violent video game play and aggression among adolescents. Developmental Psychology, 48, 1044-1057. http://dx.doi org/10.1037/a0026046

Received June 12, 2017

Revision received March 21, 2018 Accepted April 25, 2018

\section{E-Mail Notification of Your Latest Issue Online!}

Would you like to know when the next issue of your favorite APA journal will be available online? This service is now available to you. Sign up at https://my.apa.org/portal/alerts/ and you will be notified by e-mail when issues of interest to you become available! 